\title{
The Impact of Pipeline Pressure on Hazardous Area of Lox leakage
}

\author{
Hua Wang ${ }^{1, a}$, Donglei Fan ${ }^{1,2, b}$, Cunyan Cuil,c, Ningyuan Liu' ${ }^{1, d}$, Xiao Luan $^{2}$ \\ ${ }^{1}$ The Academy of Equipment, Beijing 101416, China, \\ ${ }^{2} 63618$ Troops of the People's Liberation Army, Korla 841001, China. \\ afdl131218@163.com, b269027762@qq.com, 'ccy6655@126.com, ${ }^{\mathrm{d}} 2011 \mathrm{jixie}-$ \\ Iny@alumni.sjtu.edu.cn
}

Keywords: lox, fuel coupler, pipeline pressure, hazardous area.

\begin{abstract}
Non-toxic, pollution-free loading system of lox is used in new launch vehicles. In the progress of loading or venting lox, the accident detachment of fuel connector will lead to leakage and diffusion of lox. Low temperature and oxygen enrichment caused by lox leakage will bring great damage to workers and equipment. Numerical model of oxygen leakage and diffusion is established and calculated. The spatial range and duration of the hazardous area are analyzed according the simulation. The result shows that the spatial range and duration of hazardous area increase with the raise of pipeline pressure. Operators of aerospace launch site should keep away from the hazardous area during the specific time slot, and handle the accident effectively on the basis of adequate protection.
\end{abstract}

\section{Introduction}

With the rapid development of space technology in China, the new launch vehicle with non-toxic, pollution-free lox and liquid hydrogen goes into service. The technology state, the operating procedure and the staff structure are all new. In the progress of loading or discharging lox, once fuel connector falls off by accident, it will not dock automatically again [1]. Operators need to link it up manually, and to complete several operations during this progress, such as taking the engine protection, removing the ladder and removing the cover of active platform [2]. If lox left in the rigid pipe and soft pipe cannot be handled in time, it will lead to short time, slow lox leakage, which will possibly bring damage to workers and equipment. This thesis focuses on the progress of lox leakage, analyzes the spatial range and duration of hazardous area under different pipeline pressures, in order to provide references for contingency plans and protective measures.

\section{Modeling}

The temperature of lox is low. Lox is easy to produce abnormal pressure and flammable and explosive with the characteristics of low boiling point, low latent heat of evaporation and strong penetration [3]. When the fuel connector falls off accidentally, leaking lox at the instant will quickly vaporize under normal temperature and atmospheric pressure, and form an oxygen-rich area of certain pressure for a short of time. Due to the sudden changes of pipeline pressure, residual lox in the filling pipeline will continue to leak slowly under the control of one-way valve in loading system until the pressure difference is zero, causing the formation of local hazardous area. With the large amount of lox evaporating, the concentration of hydrocarbons in the local area of the source may also increase. The risk of fire and explosion is much greater than that of the gaseous oxygen [4].

In this section, the simulation is carried out. The ambient temperature is $300 \mathrm{~K}$, and the atmospheric pressure is $0.1 \mathrm{MPa}$, with vertical gravity. The average diameter of leakage hole is used, which is circular and set as free flow outlet. The leak model is simplified to a two-dimensional model as shown in Fig.1. The diameter of the pipeline is $150 \mathrm{~mm}$ and the length of the pipe is $23 \mathrm{~m}$. In order to improve the accuracy of the meshing grids, the grids near the leak hole are encrypted. The calculation range is $200 \mathrm{~m} \times 200 \mathrm{~m}$. 


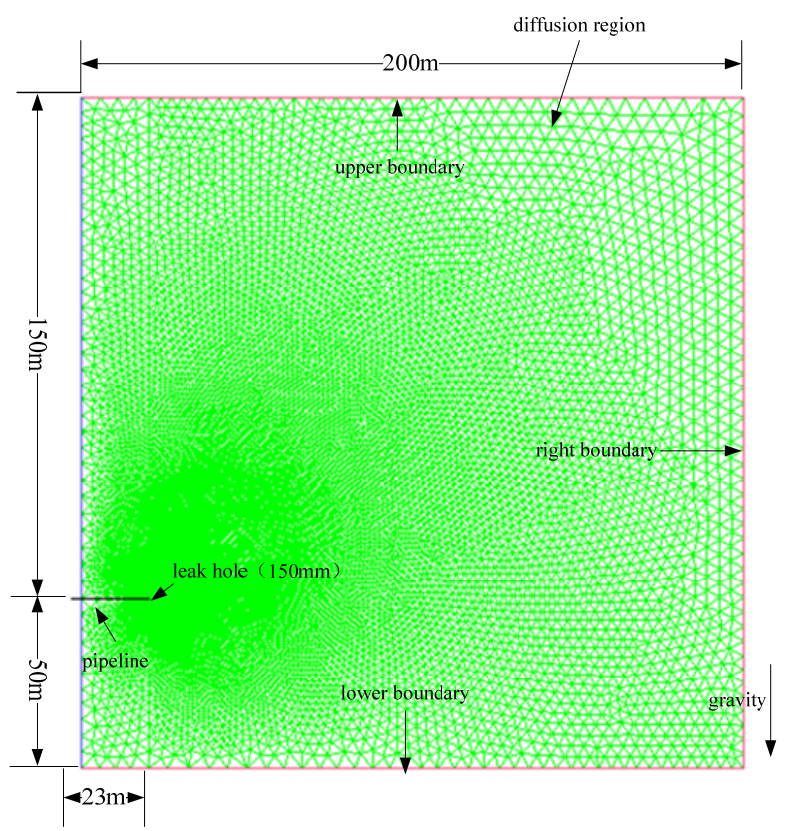

Fig.1 Geometric model and mesh

\section{The Impact of Pipeline Pressure on Hazardous Area}

Due to the actual filling process of the cryogenic propellant, the pressure in the loading pipeline connected to the first stage is constantly changing. The pressure in the pipeline when the fuel connector falls off accidentally is unsure as well. In this section, according to the range of pressure value during the discharge of lox, the impact of different pipeline pressure on hazardous area is studied. The pressure values of the pipeline are $0.3 \mathrm{MPa}, 0.4 \mathrm{MPa}, 0.6 \mathrm{MPa}, 0.8 \mathrm{MPa}, 1.0 \mathrm{MPa}$ and 1.2 MPa for analysis.

\subsection{The Impact of Pipeline Pressure on Mass Flow}

From Fig.2, the mass flow tendency of the leakage with the time is consistent under different pressure values, but the values of mass flow is affected by the pressure of the pipeline. The greater the pressure value of the pipeline, the larger the mass flow rate of the pipe is. With the increase of pipeline pressure, the time required to achieve the mass flow balance value is also longer.

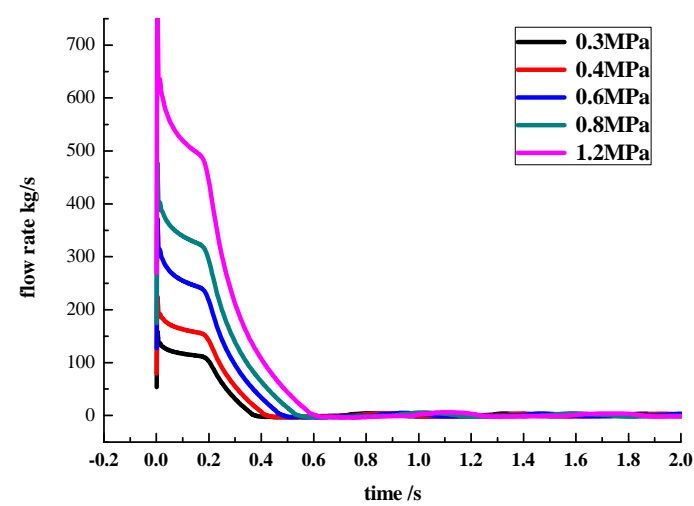

Fig. 2 Variation curves of mass flow rate with time under different pipe pressures

At $0.3 \mathrm{MPa}$, due to the maximum pressure difference inside and outside the pipeline, the maximum mass flow rate of the leakage is $150 \mathrm{~kg} / \mathrm{s}$ and the value stabilizes at values about $0 \mathrm{~kg} / \mathrm{s}$ after the time of $0.4 \mathrm{~s}$. Under the pressure of $0.8 \mathrm{MPa}$, the maximum mass flow rate reaches $400 \mathrm{~kg} / \mathrm{s}$. The maximum mass flow rate increases to $650 \mathrm{~kg} / \mathrm{s}$ under $1.2 \mathrm{MPa}$, which is 3 times as much as that of $0.3 \mathrm{MPa}$. Besides, the time to reach balance increases to $0.6 \mathrm{~s}$. The values of the mass flow will inevitably affect the area of the dangerous oxygen cloud outside the pipeline. In the next section, the distribution of oxygen concentration under different pipeline pressures will be studied. 


\subsection{The Impact of Pipeline Pressure on Oxygen Concentration}

From Fig.3, the oxygen concentration hazardous area at the same time outside the pipeline leak hole changes with the pipeline pressure difference inside and outside. The lateral diffusion distance from the leak surface is from $7.02 \mathrm{~m}$ under $0.4 \mathrm{MPa}$ to $10.652 \mathrm{~m}$ under $1.2 \mathrm{MPa}$, and the longitudinal diffusion distance is from $5.689 \mathrm{~m}$ under $5.3 \mathrm{MPa}$ to $9.32 \mathrm{~m}$ under $1.2 \mathrm{MPa}$. The risk of fire in the same area is also increasing with the increase of oxygen concentration.

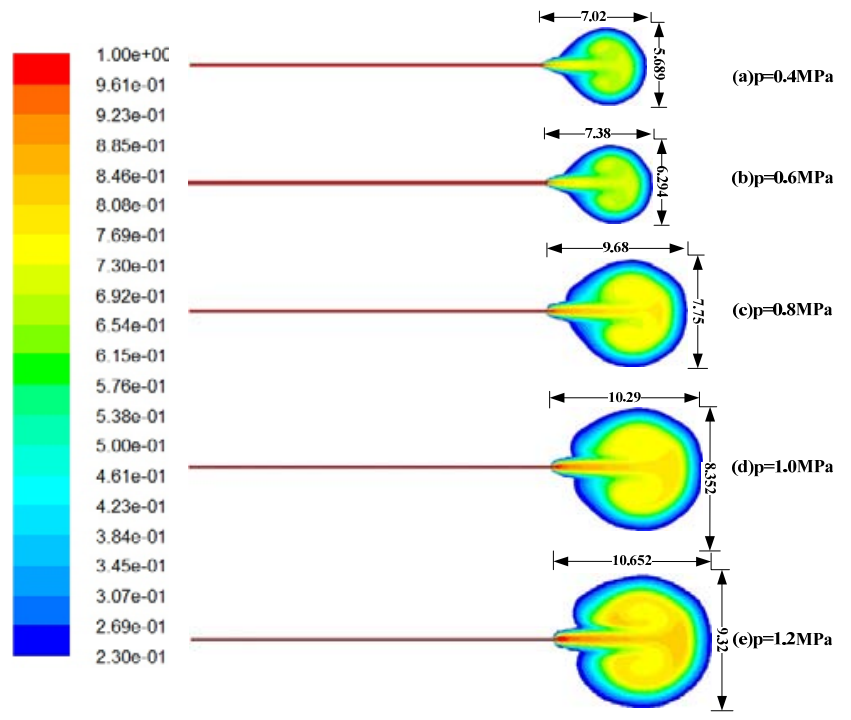

Fig. $3 t=0.1$ s, the oxygen concentration of the dangerous area under different pressures ( $23 \%-100 \%)$

From Fig.4, when the pipe pressure is $0.3 \mathrm{MPa}$, fuel connector accidentally falling off at $0.1 \mathrm{~s}$ will produce $6.85 \mathrm{~m} \times 5.11 \mathrm{~m}$ low-temperature dangerous oxygen cloud. As time goes on, more and more air is sucked into the oxygen cloud in the effect of atmospheric turbulence. The hazardous area spreads to $16.639 \mathrm{~m} \times 15.33 \mathrm{~m}$ at $3.0 \mathrm{~s}$. The oxygen concentration of the dangerous area is diluted to $23 \%$, and the risk is gradually reduced.

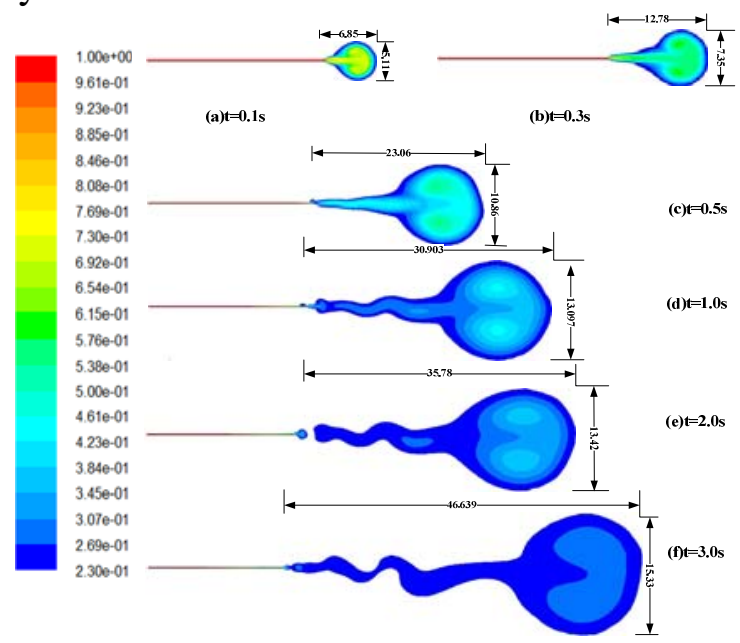

Fig. $4 \mathrm{p}=0.3 \mathrm{MPa}$, dangerous area with time changes in the oxygen concentration cloud ( $23 \%-100 \%)$

As shown in Fig.5, when the pipeline pressure is $1.2 \mathrm{MPa}$, leak hole at $0.1 \mathrm{~s}$ forms a dangerous lowtemperature oxygen cloud with the size of $11.13 \mathrm{~m} \times 9.27 \mathrm{~m}$. Compared to $0.3 \mathrm{MPa}$, the risk range expands to nearly 3 Times. At 1.0s, horizontal diffusion distance of the former has reached $63.806 \mathrm{~m}$, even $17.167 \mathrm{~m}$ father than the distance the latter spread to at $3.0 \mathrm{~s}$. The size of the pressure value of the risk area. In the later stage of lox diffusion, the inertial force of lox caused by the pressure difference of the pipeline is weakened. At 3.0s, the oxygen concentration in the hazardous area has decreased to $23 \%$ under 1.2MPa. 


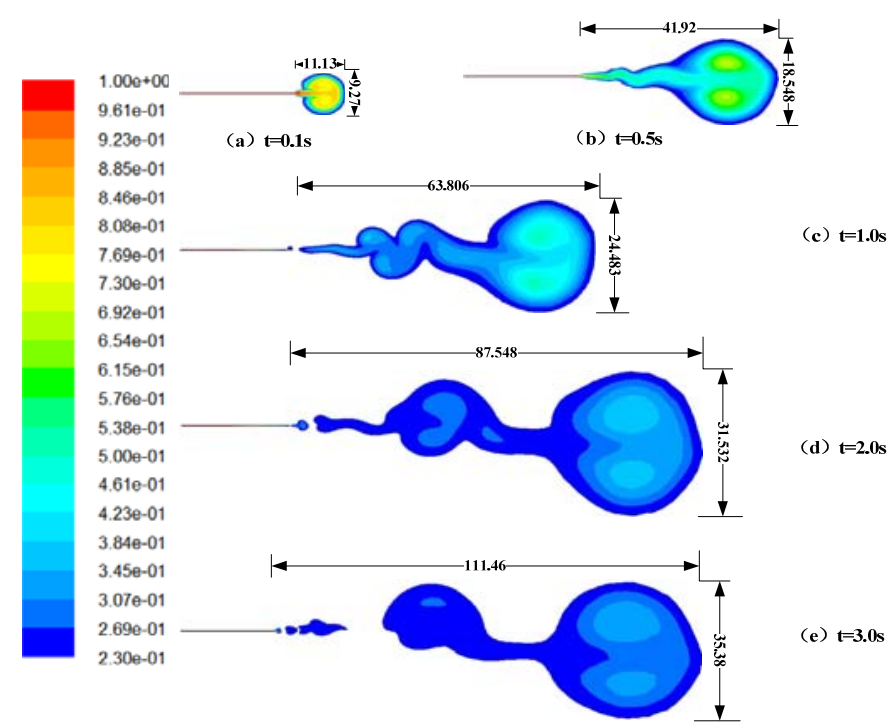

Fig.5 $\mathrm{p}=1.2 \mathrm{MPa}$, dangerous area with time to change the oxygen concentration cloud $(23 \%-100 \%)$

From the comparison above, the oxygen concentration value changes with time can be concluded as follows. When lox discharge connector of first stage accidentally falls off, lox leakage causes a hazardous area with high oxygen concentration. To avoid the impact of oxygen-enriched environment, the technical staff must stop any operation on connector and keep the distance over $111.46 \mathrm{~m}$ outside the leakage in the 3.0s under any pressure. The minimum distance is $46.639 \mathrm{~m}$ under $0.3 \mathrm{MPa}$. There is the risk of fire in the lengthways distance from $15.33 \mathrm{~m}$ to $35.38 \mathrm{~m}$.

\section{Conclusion}

From the research above, once lox leakage happens, the mass flow of lox after the leakage is relatively large consistent with pipeline pressures. The oxygen concentration hazardous area and frostbite hazardous area increase with the pressures inside and outside the pipeline.

\section{References}

[1]. Cui Erwei. Study on the integrated umbilical automatic docking and undocking connector of launch vehicle [D].Nanjing: Nanjing University of Science and Technology, 2014.

[2]. Wang Ruiquan. The development and prospect of the large-scale launch vehicle ground support system [J]. Missiles and space vehicle, 2000, 243(1):25-28.

[3]. Zhong Yikui. The simulation experiment study of circulating chilldown of cryogenic liquid rocket engine [D].Zhejiang: Zhejiang University, 2003.

[4]. Wang Ailing. Analysis on the dangers of LOX and the safety protection technology [J]. Manned spaceflight, 2008(3):19-21. 